\title{
Environmental issues in sustainable use of water from minor and medium rivers in the Yenisei River Basin District
}

\author{
Evgeniia Kolesnikova* \\ Ecological Department, Russian State Hydrometeorological University, 192007, 79 Voronezhskaya \\ Str., Saint Petersburg, Russia
}

\begin{abstract}
Minor and medium rivers of the Russian North regions are vulnerable to anthropogenic impact. The article deals with the water use problems in the Yenisei River Basin where about $90 \%$ of the rivers used for water supply are minor and medium. Aassessment of the main sources of anthropogenic impact at the rivers of the region is given. The article substantiates the main problems in sustainable use of water in the Yenisei River Basin, such as water pollution, regulation of river flow and water resource depletion. The methods of estimation of acceptable water intake are analyzed, empirical and analytical probability curves of water intake values for each season for eleven rivers are built. Environmental flow for eleven rivers, as the average month and average annual values, are calculated.
\end{abstract}

\section{Introduction}

Issues of minor and medium rivers in the northern regions are rather multifaceted, i.e. when the rivers are being used, the issues concerning water deficit and low-quality water, which are closely tied to the problems described above, occur. The Yenisei River Basin is located in the centre of Asian continent and it is one of the largest basin areas in Russia. Almost half of the Yenisei Basin District is located beyond the Polar Circle. Nowadays, in the Yenisei Basin District, about $90 \%$ of the rivers used for water supply are minor and medium [1]. Severe climate and perennially frozen rocks in the Arctic area determine short period of their free channel, there is a long term of winter low-water and short runoff period. Thus, streamflow within this area is dominated by rainfall and snowmelt sources. The majority of the minor and medium rivers freeze partially or completely, to their bed. That makes minor and medium rivers of the North very vulnerable to anthropogenic impact.

\footnotetext{
*Corresponding author: ayyoga@yandex.ru
} 
The largest part of water in the Yenisei Basin District (77\%) is used as industrial water by power sector companies. The territory of the Yenisei Basin District is abundant in mineral resources and raw materials. The largest oil and gas deposits are located in the Turikhansky and Taymyrsky Districts; in the south of the Evenkiysky District there are the deposits of Urubcheno-Takhomskaya area. The intensity of anthropogenic load on the water facilities in the Yenisei Basin District is changing from insignificant to high due to natural water intake and discharge of sewage water.

We can highlight three core geoenvironmental issues in sustainable use of water from the minor and medium rivers in the Yenisei Basin District.

The first issue is water pollution. The most crucial source of pollution and negative impact on the ecosystem of the Arctic area of the Yenisei Basin District is the production facilities of Mining and Metallurgical Company «Norilsk Nickel» mining for copper, nickel, cobalt, and platinum. The river basins in Taymyr are also being polluted due to utility companies, oil bulk plants, fuel and lubricant storages, diesel boiler houses, garages, as well as due to emergencies in oil pipelines. Unlike oil spillage in the areas with moderate climate, natural self-cleaning in the Far North can take the decades rather than years. Liquidation of oil spills in condition of snow and ice cover is a very complicated procedure. In the regions of the Extreme North the processes of oil evaporate and decompose go more slowly than in warm geographical zones. Petroleum products are accumulated at the oil field all winter and during floods and ice drifting go into the rivers. There is no explicit trend of surface water quality improvement or deterioration in the Yenisei Basin District over the past several years.

The second issue is related to regulation of river flow. In Yenisei Basin, there are seven water reservoirs with the total volume exceeding $10 \mathrm{M} \mathrm{m}^{3}$. Within the Arctic area, the water reservoirs are built on the Kureyka River and the Khantayka River [2, 3]. As a result, there are not only increase in water resources, but also a great reduction of flow speed, changes in water regime of water flows and in microclimate of the adjacent territories. The creation of large water reservoirs in the Yenisei Basin resulted in the changes of natural water regime. Besides, some changes in the temperature regime occurred, the timeframe of maximum water temperatures and freeze-up on the vast areas in the downstream of the reservoirs was shifted. Shore erosion processes and landslides are activated due to functioning of water reservoirs. The consequences of flow regulations impact the changes in fish species composition, reduction of fish capacity. Besides, the creating of reservoirs led to the increase in ground water levels, the flooding of habitable areas and agricultural lands.

The third geoinvironmental issue of the Yenisei Basin District is water resource depletion. In general, the Arctic area is characterized with excessive wetness. Low temperatures lead to low evaporation which does not exceed the precipitation, though the latter is relatively small. The Arctic area is characterized by high modulus of flow, high density of river network, and abundance of rivers and lakes.

Field development and mining is a high water-consuming industry. For instance, while mining for coal in the Kansko-Achinsky, Tungussky, Taymyrsky and Minusinsky coal basins requires pumping out $20 \mathrm{~m}^{3}$ of water for every ton of extracted coal. Depletion of groundwater resources results in drying-out of minor rivers, creeks, and swamps. Floodlands are left without water. These are the areas where historically fish spawning and bird nesting took place. That, to great extent, impedes sustainable and safe functioning of water ecosystems in the Yenisei Basin District.

While monitoring of surface waters quality in Russia is quite well developed in a methodological sense and is supported by law, the issue of water depletion is still under consideration. So, the Russian Water Code does not set any requirements to water resource 
protection against depletion, there are no requirements to setting an environmental flow and the volume of acceptable water intake from water facilities.

\section{Methods}

Many researchers $[4,5,6]$ point out that water resources of rivers and water bodies cannot be fully discharged for the need of the economy. The significant part of them should be left for environmental flow in river systems for preserving ecosystem sustainability. In this paper, we use the methodology of V.G. Dubinina to calculate the environmental flow and acceptable water intake, in which a water body is viewed as an integral geobiological system, the sustainability of whose functioning is defined with the current balance in all the ecosystem components [5].

Comparing the critical water discharge and volumes $\left(\mathrm{Q}_{\mathrm{cr}}\right.$ and $\left.\mathrm{W}_{\mathrm{cr}}\right)$ with the historical minimum discharges (volumes), we identify that part of the river discharge which can be taken from a water body without any appreciable damage to natural reproduction of the number of hydrobionts during low-water years. The volume for acceptable non-recoverable water intake $\mathrm{W}_{\mathrm{di}}$ for every month is defined as the difference between the critical minimal water volume $\mathrm{W}_{\mathrm{cr}}\left(97 \%\right.$ probability) and historically minimal volumes $\mathrm{W}_{\text {hist }}(99 \%$ probability). The baseline flow $\left(\mathrm{W}_{\mathrm{b}}\right)$, i.e. minimal flow, is the baseline from which a water intake of flow amounting to $\mathrm{W}_{\mathrm{di}}$, is calculated as a sum of the critical minimal volume $\mathrm{W}_{\mathrm{cr}}$ ( $97 \%$ probability) and historically minimal volume $W_{\text {hist }}(99 \%$ probability). Then, based on the estimated volumes of the acceptable water intake, the environmental flow $\left(\mathrm{W}_{\mathrm{er}}\right)$ for every month is calculated as the difference between the volume of the natural monthly flow $\mathrm{Wi}$ and the volume of the acceptable water intake of water $\mathrm{W}_{\mathrm{di}}$.

This paper encompasses the study of 2 minor and 9 medium rivers in the Yenisei Basin District. The benchmark data are average monthly water water intake from 1938 to 2013. Taking into account the available monthly water discharge rows, we have calculated the water discharge of varied probability for each month.

\section{Results}

To select the optimal law of distribution for each point of observation, empirical and analytical probability curves were constructed for each month. For instance, Fig. 1 and 2 present low-water (March) and full-water (July) stages of the water regime for the Dubches River. The graph shows the best probability curve with the two closest to it curves. For all the rivers mentioned, the best ratio is $\mathrm{Cs}=2 \mathrm{Cv}$.

After selecting the best analytical probability curves, they served to identify the values of water discharges with the probability of $95 \%, 97 \%$ and $99 \%$, required for environmental flow calculation and the acceptable discharge. The graphs were drawn for the baseline, environmental flow and the acceptable discharge. Based on multiyear monthly benchmark data, we drew standard flow intake hydrograph for all the eleven points of observation. For instance, in Fig. 3 and 4, one can see the streamflow hydrograph for a multiyear period, baseline and environmental flow hydrograph, as well as the acceptable water discharge for the Dubches and Sovetskaya Rechka rivers. 


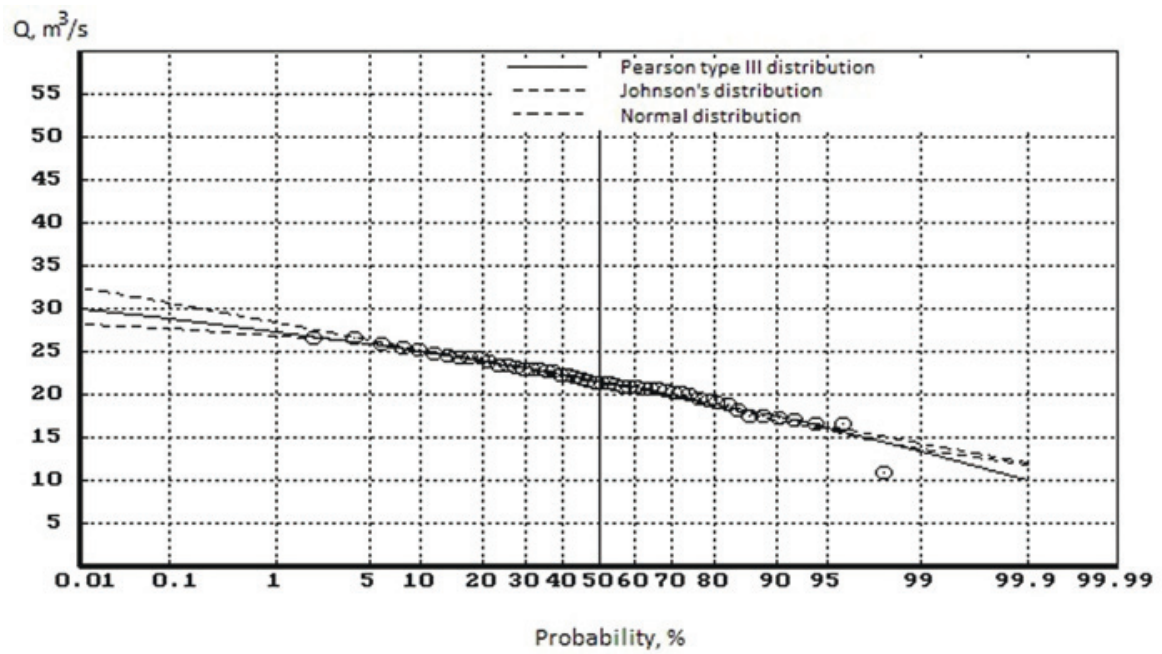

Fig. 1. Empirical and analytical probability curves for water intake in March, the Dubches River Sandakches Settlement.

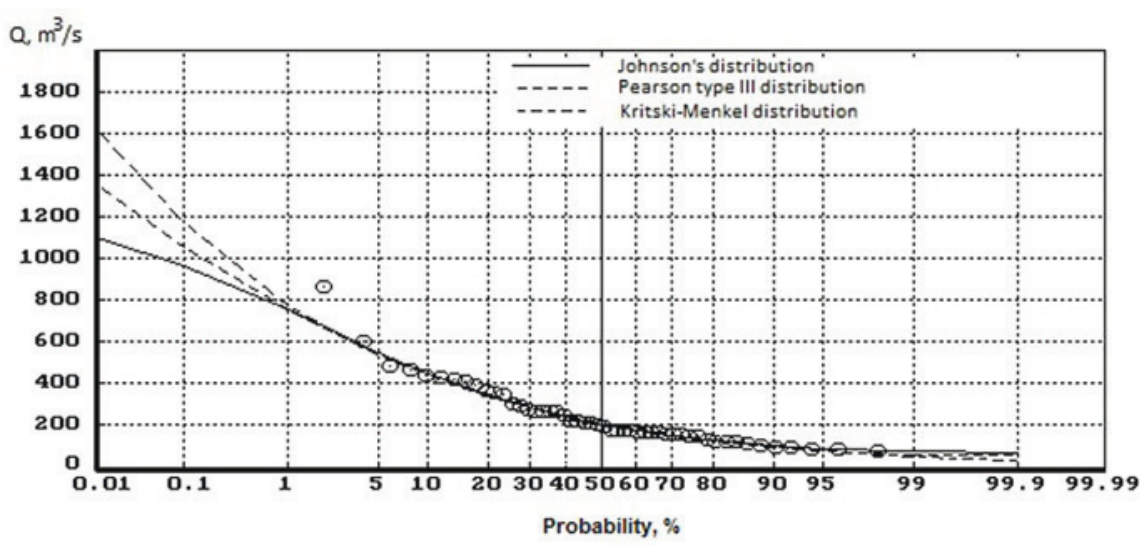

Fig. 2. Empirical and analytical probability curves for water intake in July, the Dubches River Sandakches Settlement.

For all the eleven rivers under study, the main characteristics and calculated values of water use are presented in Table, where one can see the estimated values of baseline flow, environmental flow, acceptable water intake for average annual period. The values of the average environmental flow volumes depend on annual rives flow and can be very small. So during winter flow (from December to April) for minor rivers the volumes of the acceptable water intake are close to zero, which makes it impossible to intake flow for water use reasons over that period. The maximum of the above values are mainly seen during full-water periods from April-May to July-August. There are no water deficits observed over spring and summer periods. In autumn, from August to September, there is a sharp drop in the volumes of baseline flow which results in bringing down the levels of the environmental flow and the acceptable water intake. 
Table. The main characteristics and estimated values of water use for minor and medium rivers of the Yenisei River Basin.

\begin{tabular}{|c|c|c|c|c|c|c|c|c|c|c|c|c|}
\hline \multirow{2}{*}{\multicolumn{2}{|c|}{$\begin{array}{c}\text { Rivers } \\
\text { Characteristics }\end{array}$}} & \multicolumn{9}{|c|}{ Medium rivers } & \multicolumn{2}{|c|}{ Minor rivers } \\
\hline & & 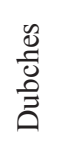 & 泀 & $\begin{array}{l}\overrightarrow{\overrightarrow{0}} \\
\frac{0}{\text { 피 }}\end{array}$ & 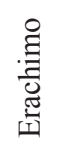 & $\underset{E}{\stackrel{\Xi}{\Xi}}$ & 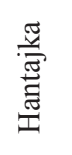 & 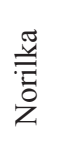 & 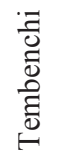 & 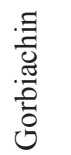 & 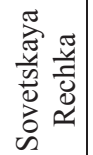 & 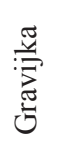 \\
\hline \multicolumn{2}{|c|}{$\begin{array}{l}\text { Basin area, ths. } \\
\mathrm{km}^{2}\end{array}$} & 15,3 & 11,5 & 25,1 & 9,1 & 35,8 & 30,7 & 19,8 & 21,6 & 6,3 & 1,8 & 0,3 \\
\hline \multicolumn{2}{|c|}{ River length, km } & 433 & 232 & 464 & 218 & 639 & 174 & 57 & 571 & 239 & 98 & 45 \\
\hline \multicolumn{2}{|c|}{$\begin{array}{l}\text { Mean annual } \\
\text { discharge (Q), } \\
\mathrm{m}^{3} / \mathrm{s}\end{array}$} & 88,4 & 68,3 & 161 & 145 & 111 & 272 & 454 & 257 & 71,1 & 15,5 & 5,1 \\
\hline \multicolumn{2}{|c|}{$\begin{array}{l}\text { Annual flow } \\
\text { volume (W), } \mathrm{km}^{3}\end{array}$} & 232 & 180 & 422 & 381 & 261 & 716 & 1193 & 676 & 187 & 40,8 & 13,3 \\
\hline \multirow{2}{*}{$\mathrm{B}$} & $\mathrm{Q}, \mathrm{m}^{3} / \mathrm{s}$ & 45,4 & 33,8 & 86,8 & 59,7 & 61,1 & 162 & 258 & 126 & 31,7 & 7,75 & 1,87 \\
\hline & $\mathrm{W}, \mathrm{M} \mathrm{m}^{3}$ & 119 & 88,9 & 228 & 157 & 161 & 427 & 679 & 332 & 83,2 & 20,4 & 4,87 \\
\hline \multirow{2}{*}{$\mathrm{E}$} & $\mathrm{Q}, \mathrm{m}^{3} / \mathrm{s}$ & 31,9 & 25,0 & 70,5 & 31,3 & 34,5 & 142 & 203 & 110 & 26,9 & 5,34 & 0,84 \\
\hline & $\mathrm{W}, \mathrm{M} \mathrm{m}^{3}$ & 83,9 & 65,8 & 185 & 82,3 & 90,8 & 373 & 534 & 291 & 70,6 & 14,1 & 2,22 \\
\hline \multirow{2}{*}{ A } & $\mathrm{Q}, \mathrm{m}^{3} / \mathrm{s}$ & 9,29 & 6,17 & 11,46 & 19,5 & 14,0 & 14,8 & 37,8 & 12,0 & 3,61 & 1,65 & 0,70 \\
\hline & $\mathrm{W}, \mathrm{M} \mathrm{m}^{3}$ & 24,4 & 16,2 & 30,1 & 51,3 & 36,8 & 38,8 & 99,4 & 31,4 & 9,49 & 4,35 & 1,85 \\
\hline
\end{tabular}

$\mathrm{B}$ - baseline flow, $\mathrm{E}$ - environmental flow, $\mathrm{A}$ - acceptable water intake.

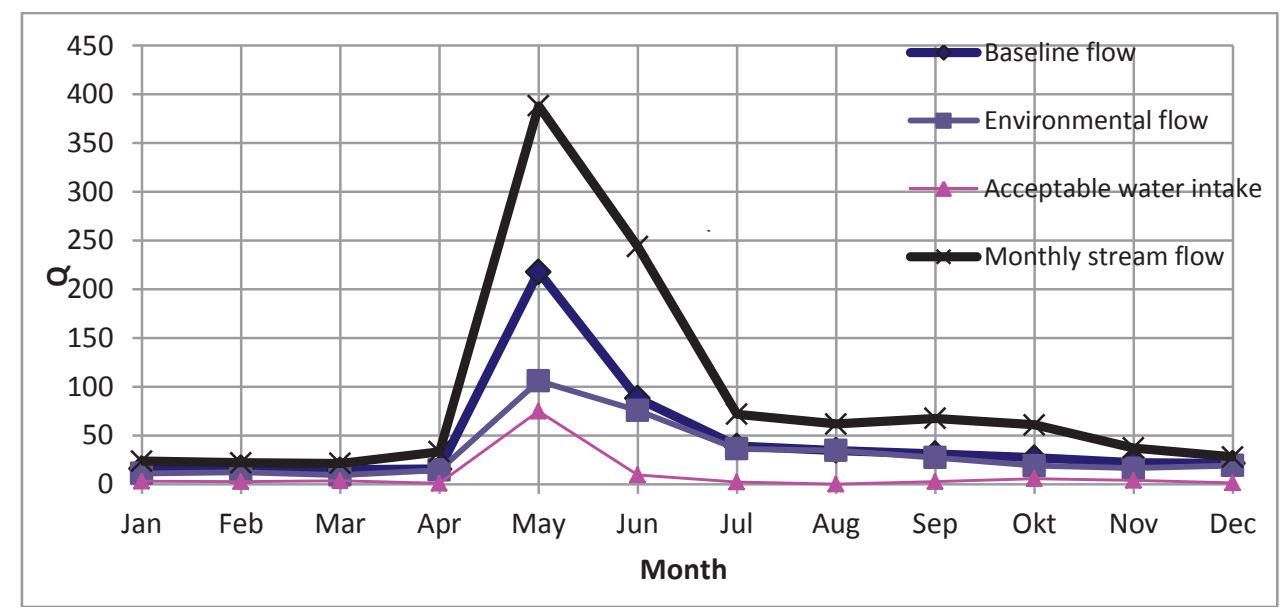

Fig. 3. Flow hydrograph of baseline and environmental flow and acceptable water intake from the Dubches River-Sandakches Settlement, $\left(\mathrm{Q}, \mathrm{m}^{3} / \mathrm{s}\right)$. 


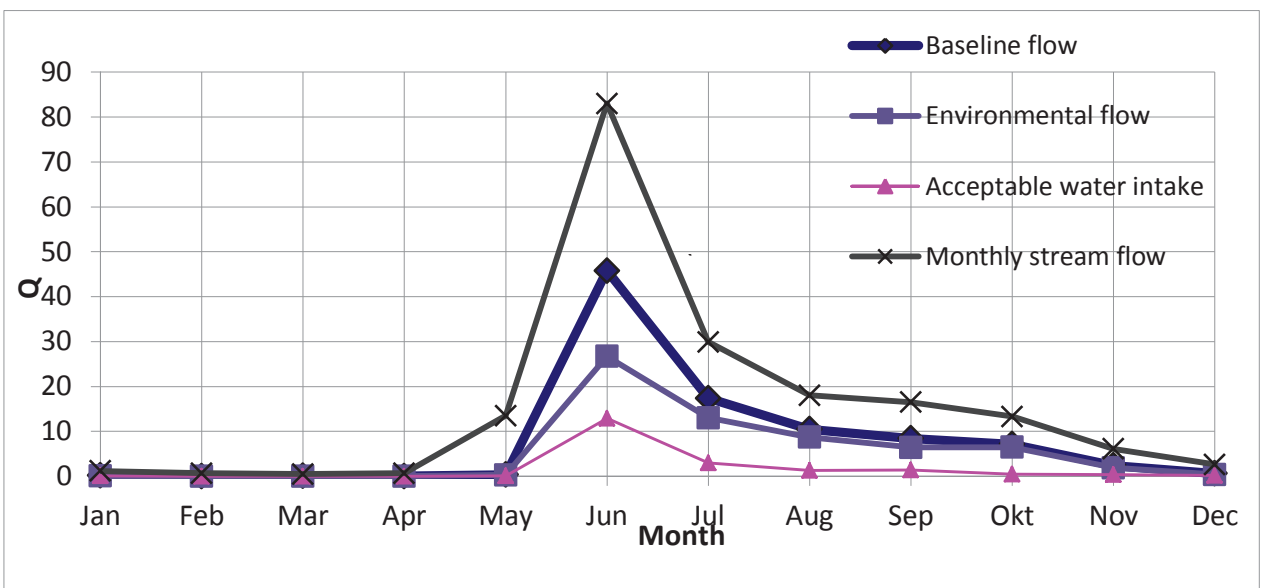

Fig. 4.Flow intake hydrograph of baseline and environmental flow and acceptable water intake from the Sovetskaya Rechka River - Sovetskaya Rechka Settlement, $\left(\mathrm{Q}, \mathrm{m}^{3} / \mathrm{s}\right)$.

\section{References}

1. Arctic Encyclopedia, M., «Paulsen», 2 (2017)

2. Environmental State Assessment and Core Issues of the River Basin, Diagram illustrating Complex Use and Protection of Water Facilities in Yenisei Basin,2 (2018)

3. N.M. Novikova, Zh.V.Kuz'mina, S.A. Podol'skiy, T.V. Balyuk, Environmental Validation of Approaches to Setting Standards for Regulation of River Flow. Volga Ecological Journal (2005)

4. B.V. Fashchevskiy, Environmental Validation of the Acceptable Degree of River Flow Regulation. BelNIINTI (1989)

5. V. G. Dubinina, Methodology for Setting Environmental Standards for Nonrecoverable Flow Discharge and Setting Environmental Flow (Economics and IT, 2001)

6. Z.K. Iofin, Environmental Validation of Residual Minimal Water Discharge,Fundamental Problems of Water\&Water Resources Use and Studies, GI under the Siberian Branch of the RAS (2005) 